While some libraries struggle with the whole idea of embracing marketing, and others do it piecemeal off the side of their desks, San Antonio Public Library has dedicated an entire team to their marketing and communications. Read on to see how this unique arrangement works, and for some of the innovative ideas these non-librarians have brought to the library world.-Editors

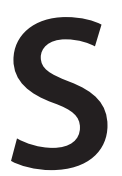
an Antonio Public Library (SAPL) takes a nontraditional approach to library marketing: there are no librarians on our marketing team. We operate as an in-house boutique agency comprised of specialists in media, public and community relations, graphic design, marketing, and communications strategy. As the community and public relations manager, I oversee a team of seven that includes three full-time graphic designers, two marketing specialists, a public information officer, and a community relations coordinator. As a team we are responsible for marketing the entire SAPL system of thirty locations, including Central Library. Despite our independence, we would not be nearly as effective as a marketing team if we did not have many successful partnerships and collaborations with our librarians. They are brilliant, creative souls who know the library industry best and help us to be successful. We hope we do the same for them.

Our graphic designers are responsible for creating visually appealing pieces that range from directional signs to print ads, logos, and t-shirts. One marketing specialist is responsible for overseeing all logistics related to programing and rental of event space in Central Library. Among these job responsibilities is to serve as the main point of contact for the San Antonio Book Festival: a free all-day event that features over ninety national, regional, local, and emerging authors and welcomes more than 18,000 visitors. The second marketing specialist coordinates community outreach for the marketing team. She attends large city-wide community events as a representative of the library. She engages with the community regarding library resources and collects information about our community's needs. Our public information officer is responsible for writing press releases, finding news to promote, and cultivating and maintaining our relationship with the media. She also acts as the point of contact for other city departments and library partners. Finally, as the community and publication relations manager, I lead the strategic vision for the team and am responsible for internal communication between our department and the other units and departments within the San Antonio Public Library system. I also serve as liaison for any marketing 


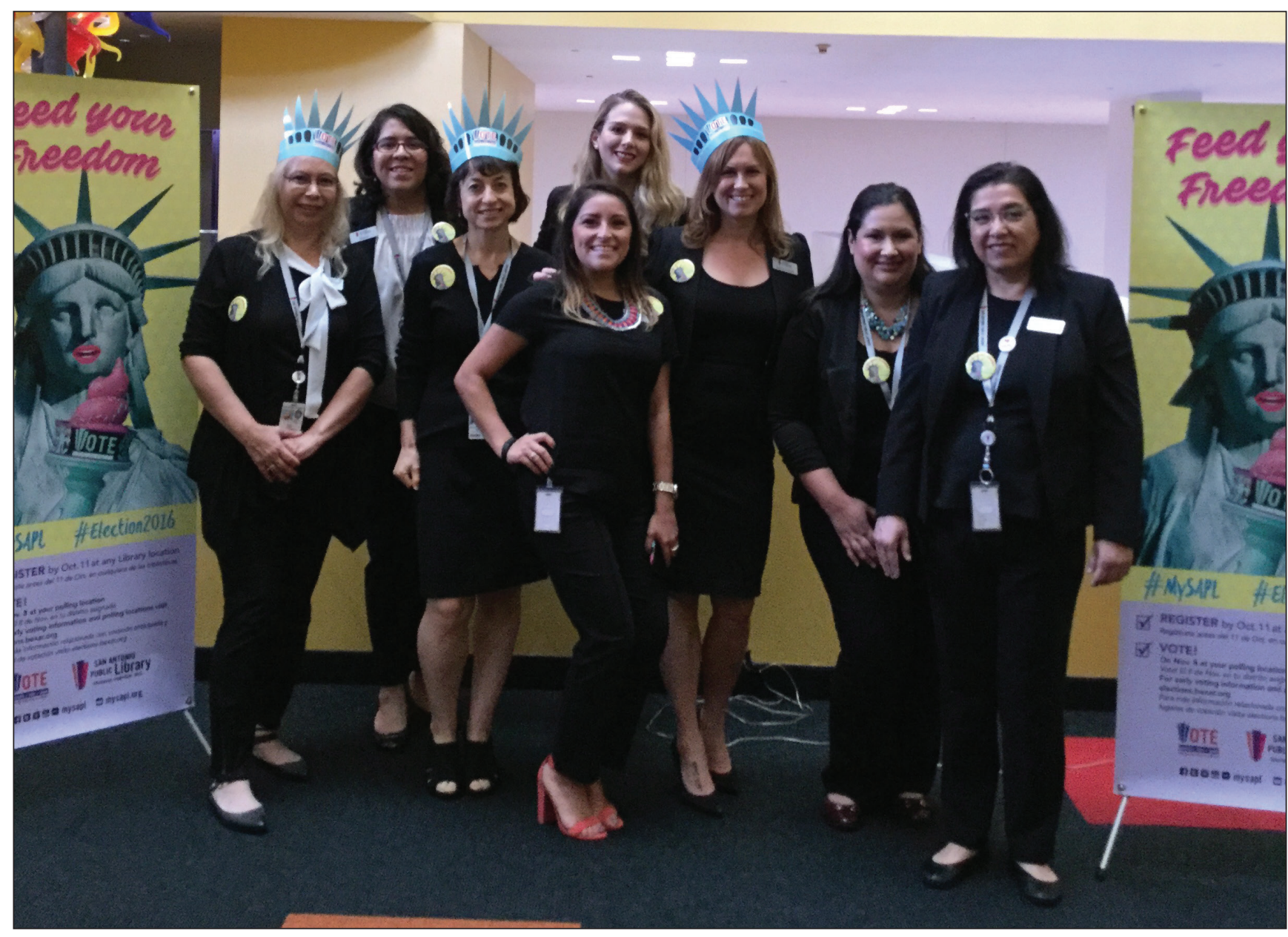

Marketing Team (left to right): Anna Farr, Graphic Designer; Regina Villalobos-Perez, Marketing Specialist; Giselle Weyte, Graphic Designer; Karla Vasquez (front), Marketing Specialist; Maria Garza (back), Graphic Designer; Caitlin Cowart, Community \& Public Relations Manager; Marcie Hernandez, Senior Public Information Officer; Esther Sanchez, Community Relations Coordinator.

needs of our Library Board of Trustees and Library Foundation. Together, our team builds comprehensive advertising, marketing, and public relations campaigns for products, programs, and services.

In 2011, during the creation of the San Antonio Public Library's 2011-2016 Five-Year Strategic Plan, the library's board chair at the time, Jean Brady, recognized that the library needed to have a larger marketing team in order to make a bigger impact in the community. The strategic plan identified key strategic initiatives: support educational and learning opportunities, support workforce and economic development, foster community connections, increase public awareness, improve organizational health, and delineate roles of board of trustees and library support groups. Brady's background in public relations before becoming a school librarian inspired the push to build a robust marketing team. What she proposed was uncommon for libraries, but she championed it as a pioneer and visionary in believing it would work - and it did.

Until that point, the library humbly (and unfairly, in the marketing team's opinion) considered itself "the best-kept secret" in San Antonio. When I joined the library team as community and public relations manager in 2013, I knew we had to turn that perception around. If the organization's employees - one of the most important advocacy and PR assets we have-continued to perceive the organization as a secret, it would keep being a secret! For an organization to be successful in the public eye, the staff members need to feel the brand deserves to be seen, talked about, loved, and enjoyed. With one of the strategic plan's priorities being public awareness, we needed to build momentum inside the organization in order to enhance our presence in the community. We needed to start believing in ourselves and believing in the journey.

Based on the foundation of the library's strategic plan, the marketing team created a marketing plan that identified key audiences and four areas of strategic focus to build on over the next two years: message alignment among external and internal stakeholders, strengthened public awareness and community engagement, identifying new audience segments, and leveraging promotional endeavors with strategic partners. This also included an updated logo and website launched in the summer of 2016. 


\section{AMPLIFY YOUR IMPACT}
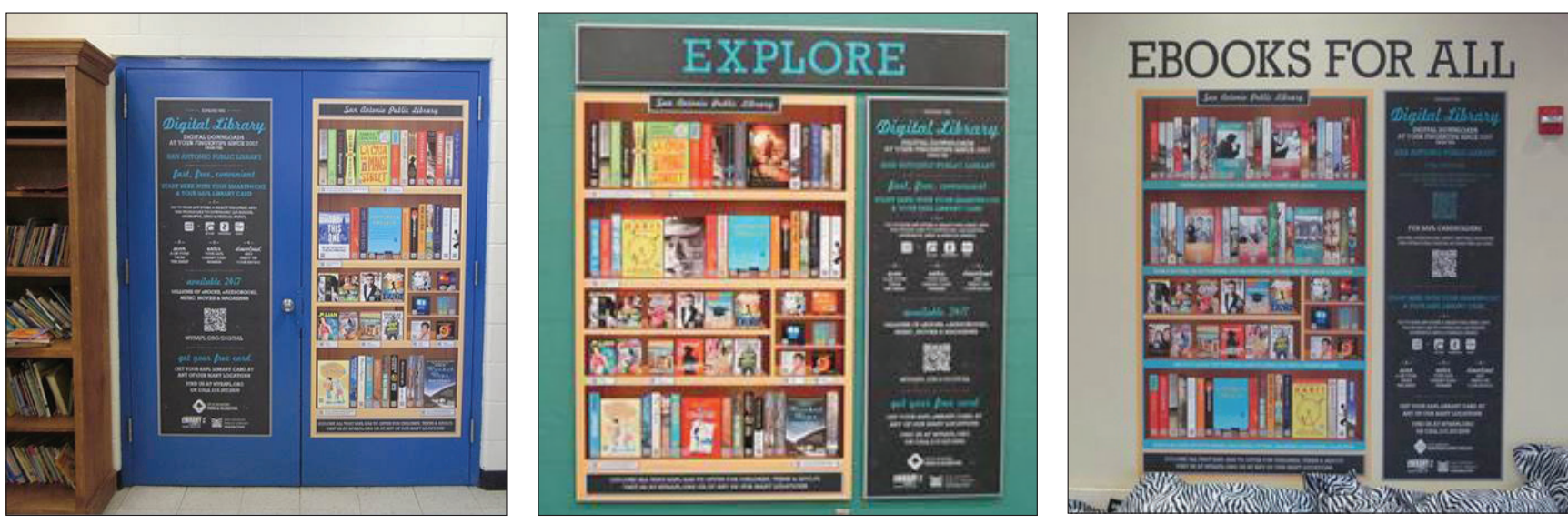

The Digital Library Community Project wallpapers serve as a gateway to San Antonio Public Library's Digital Collection. Pictured: Digital Library wallpapers at local community centers and the Henry B. Gonzalez Convention Center.

To align our message among external and internal stakeholders, we began by offering media and marketing training to our library administrative team and other library supervisors working on location with the frontline staff. The goal of the training was to encourage leadership to cultivate an environment of open communication among staff. It was important to engage the staff as our frontline advocates in the process. The marketing team worked with the library's Organizational Health Unit to support their efforts to communicate with employees. The focus of Organizational Health is to address and support the needs of SAPL employees with effective and continual communication throughout the organization; to promote creative thinking, innovation, and cohesion; and to support employees' personal career goals. Our partnership with this unit and the coupling of their mission to our own areas of focus allowed internal stakeholders to feel involved and bolstered positive attitudes. We also worked individually with members of our Board of Trustees, the San Antonio Public Library Foundation, and the Friends of the San Antonio Public Library to create targeted and succinct messages that could be shared with local leadership, donors, and others.

Our next goal, strengthening public awareness and community engagement, advanced with the creation of the Digital Library Community Project in 2014. The Digital Library Community Project, the recipient of the American Library Association's 2016 PR Xchange Award and 2016 TLA Branding Award, is a promotional initiative that was created to boost public awareness of the library's digital resources. The project is made up of a collection of Digital Library wallpapers, designed to look like bookshelves, placed city-wide at various community partner locations and three digital touch-screen kiosks at San Antonio International Airport that provide direct access to our digital collection of e-books and e-audiobooks for download. The project is key to promoting the library system's Digital Library and showcasing all that is available to the community with a free library card. We have seen a steady rise in the use of our digital collection (approximately 50 percent) since the project's 2014 launch. In fiscal year 2016, the digital collection received a 22 percent increase over fiscal year 2015. In fact, if SAPL's Digital Library were a physical location, it would have the highest circulation of all thirty library locations. Increasing the use of our Digital Library was truly a collective effort between our Digital Services and Collection Development departments and frontline advocates.

This project is a prime example of how San Antonio Public Library continues to deliver the latest on-demand products that meet the needs of an ever-mobile, internetconnected world. The initial launch of Digital Library wallpaper installations included local YMCAs, senior centers, Central Library, and the Haven for Hope homeless campus in downtown San Antonio. Since the launch, the wallpapers have expanded to twenty locations, including the Henry B. Gonzalez Convention Center, the DoSeum children's museum, and numerous public parks. The San Antonio Public Library Foundation and the Friends of the San Antonio Public Library have generously funded this project.

The creation of this project has put San Antonio Public Library at the forefront of the national library discussion by offering traditional library services outside the walls of the library. The purpose of many of SAPL's marketing campaigns is to increase public awareness in this way, and to increase use of the library's digital collections and services. We have connected with many library peers to respond to questions and exchange ideas about the project.

The Digital Library Community Project allowed us to segue into our third goal of identifying new audience segments. Because both the wallpapers and digital kiosks allowed non-SAPL cardholders access to our digital collection, we had a great opportunity to showcase our resources and services to people from San Antonio and all over the world. We were able to track usage of the Digital Library wallpaper installations by their locations, thanks to the unique $\mathrm{QR}$ codes on each title, to determine patterns that would lead us to increase access to service and resources in certain areas of 


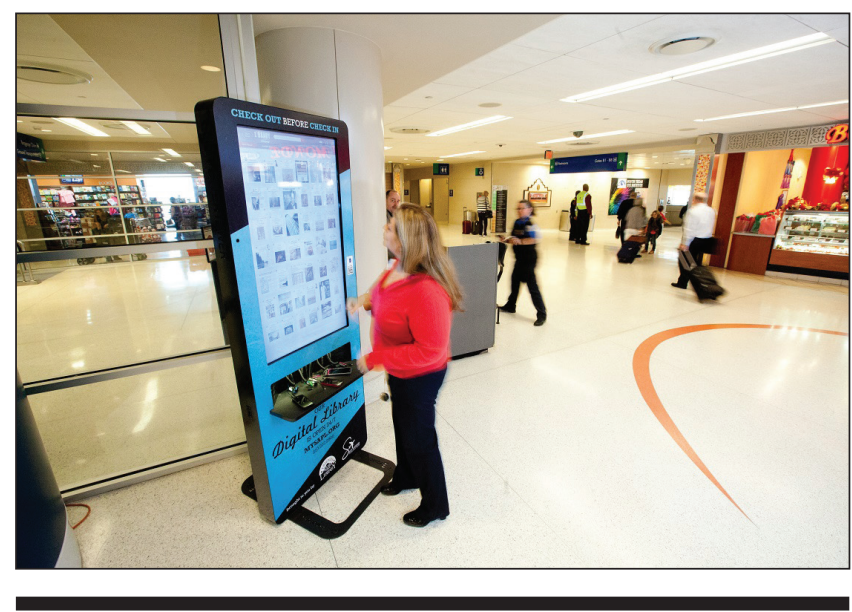

Anyone travelling through the San Antonio International Airport can access the San Antonio Public Library's digital collection with or without a library card. Pictured: Digital Library Kiosk in Terminal B at San Antonio International Airport.

the city. Recently, we have experimented with collaborations with other city departments and local community partners to offer curated collections for local themed events. For example, the local coffee festival and featured art exhibits now come with a curated digital collection link on their marketing materials. The lists are created in partnership with OverDrive and allow us to connect with new audiences in a different way.

We also followed the digital trend by investing in the creation and expansion of the San Antonio Public Library's social media presence. By developing our voice we were able to better communicate the library's mission and vision while building relationships with both cardholders and non-cardholders through Facebook, Instagram, Pinterest, Snapchat, Twitter and YouTube. SAPL has been able to cultivate relationships with millennials who we know are early adopters of technology. Tapping into this audience segment has allowed us to innovate in the way we offer traditional library services.

Our largest audience on social media is women between the ages of twenty-five and forty-four who typically engage with us most frequently on posts that highlight children's events, programs, and resources. Knowing this, we have made sure to include children's titles on the digital library wallpapers. We have also worked with children's and teen services staff to develop eReading lists for their perspective audiences. Another aspect of the library's social media presence that has proved to be successful is direct interaction between our followers and librarians and library staff. Individuals are able to build relationships with staff throughout the system, not just those who work in their community library. Social media's digital "word of mouth" marketing system has allowed our messages to spread far and wide throughout the community. Considering that 62 percent of U.S. adults consume news through social media, we know that this outlet is effective. ${ }^{1}$

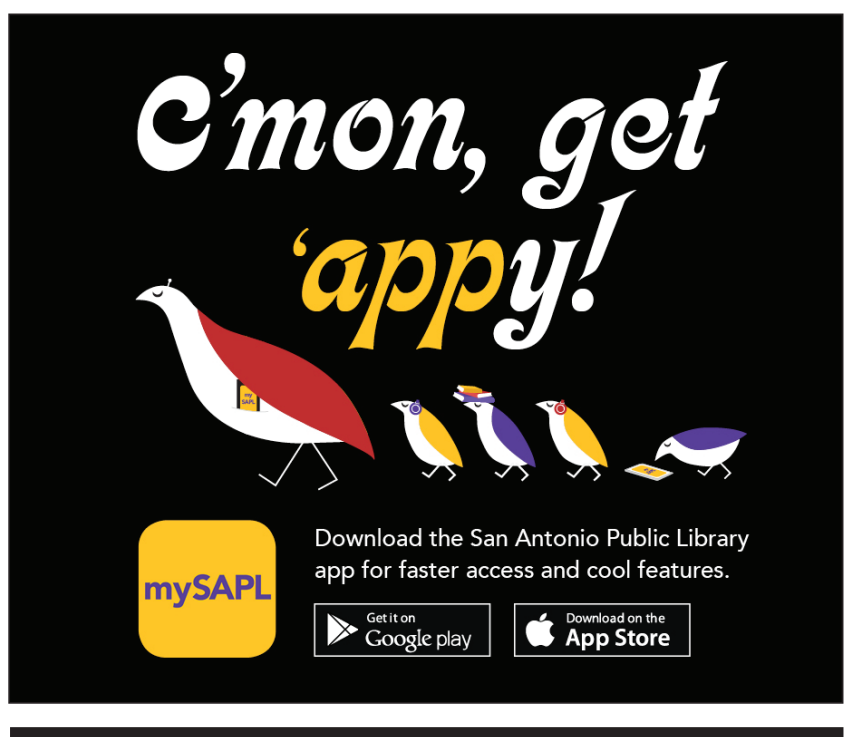

This popular marketing campaign to promote the Library's mobile app resulted in over 528,000 in-app sessions in 2016.

Another development within the San Antonio Public Library system that allowed us to identify new audience segments was the creation of an adult services coordinator role to facilitate adult programming throughout the system. In partnership with this librarian, the marketing team was able to collaborate more effectively to create unique and innovative marketing materials to distribute for programs and events. For example, after the installation of the initial Digital Library wallpapers in 2014, the library designed and released a mobile app that allows patrons to browse, place holds, access account information, and more via mobile devices. To develop awareness of the app, the marketing team created a campaign called "Come on get 'appy" that featured retro, Partridge family-inspired graphics on t-shirts, branch signage, shelf talkers, and printed material. The "throwback" style seemed to resonate with millennials, and in 2016 the MySAPL app hosted over 528,000 sessions. While we had worked with children and teen adult services coordinators, this was the first time that the library had this role for adultfocused programs. Since we have been working together, we have seen a more than 30 percent increase in attendance for library programs.

We also began to work more closely with the San Antonio Public Library Foundation's First Edition Society. This group of young San Antonians supports the mission of the San Antonio Public Library Foundation by working to engage and cultivate the next generation of young leaders. They host events that raise money for and awareness of our library system. We have been collaborating with leaders of the group to educate their members about library programs, events, and resources that they can help us to spread the word about. In October 2016, the marketing team hosted a Harry Potter-themed Snapchat release party in partnership with the First Edition Society. Almost one hundred people attended the event, which resulted in six hundred views and 


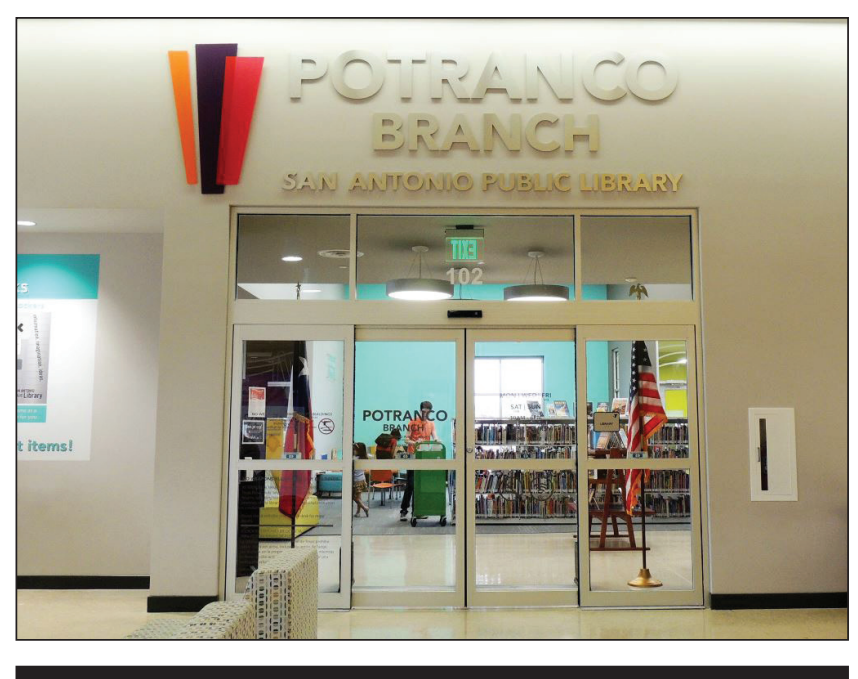

The Potranco Branch Library is the 29th location in the Library's citywide footprint. This unique and innovative space offers access to a dynamic family of services and resources and is serving as a prototype for possible future joint partnerships.

twenty-six uses of our first Snapchat filter.

Finally, we knew that to be successful we needed to leverage promotional endeavors with strategic partners. Partnering with community organizations with similar missions allows us to reach demographics that might not yet be key users of the library. This expands our reach and introduces new audiences to our services.

As previously mentioned, partnerships with our San Antonio Public Library Foundation and Friends of the San Antonio Public Library have proven to be successful. Our relationship with the Foundation, a charitable organization that works to augment the San Antonio Public Library's budget with support from individuals, corporations, and charitable foundations, has resulted in the addition of playgrounds and technology upgrades at branches, as well as purchasing advertising, marketing collateral, and social media support for the marketing team. Their members allow us to build relationships with individuals and corporations who believe in the mission and vision of the San Antonio Public Library.

The Friends of the San Antonio Public Library offer support in the form of promoting public use of the library and appreciation of its value as a cultural and educational asset to the community. With this as their mission, they act as a volunteer marketing "army," working within their individual networks to build public awareness of the library and its resources.

We are also leveraging a partnership in a new way with our co-located Potranco Branch Library at the Mays Family YMCA at Potranco. As a partnership with the YMCA of Greater San Antonio, this library serves as a destination for the Westside community and provides endless opportunities for learning and living well. This unique and innovative space offers access to a dynamic family of services and resources. Potranco Branch Library is made up of an exterior courtyard, an interactive makerspace, a quiet study area, an expanded-hours self-service lobby, and a children's discovery area. The library also provides a full-service computer area and free Wi-Fi, and of course a collection of popular materials, including vinyl records, for check out. Thanks to this project, the community can explore all that the San Antonio Public Library and the YMCA have to offer families.

This partnership has created new outlets for marketing the Library as a destination for living well. The marketing team has enjoyed brainstorming with YMCA employees to create inviting and inspiring marketing images and messages to bolster membership sales and library card sign ups.

We have other similar partnerships with groups, organizations and media partners that allow us to expand our audience reach. For example, our partnership with Alamo City Mom's Blog, a community of mommy bloggers, has allowed us to build upon their current knowledge of early literacy and story times and introduce them to our resources that they can use as entrepreneurs, creators, DIYers, readers and more. Another example of a media partnership is with the San Antonio Current, the local free publication that focuses heavily on events in the community. We were able to partner with the magazine to offer a mini-performance of the Nutcracker that drew families to Central Library and provided free advertising in exchange for the performance venue. We have also developed partnerships with organizations like the Briscoe Western Art Museum (where we have a small-scale digital library) and the Office of Historic Preservation that allow us to reach individuals with interests in history and genealogy.

Overall, we have learned that marketing libraries really does take many people working together, and we know that has been essential to our success. We attend as many of the wonderful webcasts as we can that are available through library organizations and we also seek out learning opportunities to stay ahead of trends in marketing and public relations. The library inspires us as communications professionals to continue learning and studying, always advancing in how we interact with the community. We continue to look for new ways to innovate and find unique ideas that are costeffective and impactful. I can see a big change in San Antonio Public Library's popularity not only in numbers but in the general buzz of having the word out there more often in more places. The best way to market is to put the word out there and do it consistently in various ways-doing this, success is inevitable.

\section{Reference}

1. Jeffrey Gottfried and Elisa Shearer, "News Use Across Social Media Platforms 2016," Journalism.org, accessed May 26, 2016, http://www.journalism.org/2016/05/26/news-use-across-socialmedia-platforms-2016/. 